Vol. 3, Issue 1, November 2020

\title{
STEP Forward: Combining Formal and Informal Education to Develop Communication Skills that Augment Postdoctoral Training
}

\author{
Elizabeth A. McCullough ${ }^{1}$, Eva Y. Ma², Salwa Al-Noori', and Rebecca M. Price ${ }^{4}$ \\ ${ }^{1}$ Pacific Science Center, Seattle, WA; ${ }^{2}$ School of Interdisciplinary Arts and Sciences, University of Washington, Tacoma, WA; and ${ }^{3}$ School of Science, Technology, \\ Engineering \& Mathematics and ${ }^{4}$ School of Interdisciplinary Arts and Sciences, University of Washington, Bothell \\ Keywords: Communication, Postdoctoral Fellows, Training, Classroom Teaching, Informal Education, Science Museum, Science Outreach \\ Publication Date: November 3, 2020
}

DOI: https://doi.org/10.15695/jstem/v3i1.12

\begin{abstract}
STEP Forward is a partnership between two established programs that train postdoctoral fellows in science communication: one that focuses on formal communication within college classrooms, and another that focuses on informal science communication at Pacific Science Center, a science museum. By combining these programs, postdoctoral fellows developed broad and more cohesive science communication skills. Here, we describe the components of STEP Forward and report the participants' experiences as captured by open-ended responses from surveys administered before, during, and after their training at the museum. We use content analysis to examine their perceptions of what they gained from the program. Participants indicated that they eagerly took part in public events at Pacific Science Center, gained confidence in speaking with the general public, and valued the opportunity to bring their scientific research to a broader audience. Collectively, these results indicate that STEP Forward has a positive impact on the postdocs, especially given that the postdoctoral stage is one at which scholars begin to explore different careers and skill sets. We conclude that the program is beneficial, noting that while it is currently novel, it is also a replicable and feasible model for holistic postdoctoral training and science outreach.
\end{abstract}

\section{INTRODUCTION}

Postdoctoral fellows in biomedical fields excel at research. They frequently design projects, collect data, write papers, and present at conferences. However, these skills are not sufficient for the breadth of careers they ultimately pursue (National Academy of Sciences, 2014). For example, even though almost $75 \%$ of postdocs in the life sciences express interest in careers that involve teaching (Sauermann and Roach, 2012), few postdocs have teaching experience (Rybarczyk et al., 2011). Moreover, few have formal training in communication either for academic (Cameron et al., 2015) or general (Fuhrmann et al., 2011) audiences, despite the fact that communication skills are so critical. Here, we describe a partnership between two established programs in the Puget Sound region that provides postdocs with experiences necessary for success in careers requiring a breadth of communication skills.

STEP Forward is a partnership that forged a substantial link between two established programs that trained postdocs in communication: the Science Teaching Experience Pro-
gram-Working in Science Education (STEP-WISE; STEP, n.d.) at the University of Washington (UW), and the Science Communication Fellowship (SCF) Program at Pacific Science Center (PacSci; Pacific Science Center, n.d.a.). Both established programs train postdoctoral fellows in communication. STEP-WISE is a teaching apprenticeship that focuses on formal communication within college classrooms through the development of teaching skills, while the SCF Program focuses on informal communication through strategies that support inquiry, dialogue, and engagement with the general public. This partnership was inspired by existing relationships: one of the STEP-WISE mentors (author SAN) was previously a Science Communication Fellow at PacSci, and six other postdocs had independently completed both programs.

The goal of STEP Forward was to provide postdocs who were already trained in classroom teaching (through STEPWISE) with an opportunity to expand the skills they had developed in formal education by learning and practicing 
complementary skills necessary for communicating with different audiences. In this program description, we describe briefly the two components of STEP Forward and use content analysis to interpret survey data and report on the participants' experiences. We conclude by discussing how our combined program is novel, yet contains replicable and feasible elements for promoting science communication.

\section{PROGRAMS}

Science Teaching Experience Program: Working in Science Education (STEP-WISE). STEP-WISE engages a diverse pool of postdoctoral fellows from biomedical fields at the UW and affiliate institutions in a closely mentored apprenticeship to learn how to teach scientifically with inclusive, demonstrably effective, student-centered pedagogies. Postdocs work in teams of three to develop and teach an undergraduate, credit-bearing seminar course. These STEP-WISE courses enrich undergraduate curricula with the breadth of cutting-edge topics including CRISPR-Cas9, the Zika virus, and the health implications of climate change. Because STEP-WISE training focuses on effective classroom teaching, it places an emphasis on faculty positions. STEP-WISE postdocs develop the skills and experiences necessary to be competitive for faculty positions with a significant teaching component, as well as being able to evaluate whether they want a career that involves undergraduate teaching.

STEP-WISE training consists of two initial 2-hour sessions taught by the mentors (authors EYM, RMP, and/or SAN) that introduce postdocs to backward course design (Wiggins and McTighe, 2005), Bloom's Taxonomy (e.g., Crowe et al., 2008), and active learning techniques that include the jigsaw (Aronson and Bridgeman, 1979; Clarke, 1994) and the gallery walk (Francek, 2006). The postdocs work in teams of three to find an area where their research interests intersect, and then they design a ten-class undergraduate seminar course on that topic. Each team is assigned a faculty mentor, an instructor who is experienced in scientific teaching (Handelsman et al., 2006) as well as active and inclusive learning strategies. The mentor facilitates a third 2-hour session separately with each teaching team a few weeks prior to the commencement of their teaching to consult on the team's course design and planning. During the course, the mentor observes each class meeting and debriefs with the postdoc team afterwards to discuss the strengths and weaknesses of the class and provide suggestions for improvement. More details about STEP-WISE are available elsewhere (Science Teaching Experience Program, n.d.).

STEP-WISE is funded by different communities within the UW, including the School of Medicine, the College of Arts and Sciences, the School of Interdisciplinary Arts and Sciences at UW Bothell, and the School of Science, Technology, Engineering and Mathematics at UW Bothell. It is free for participants.
Science Communication Fellowship (SCF) Program at Pacific Science Center. Pacific Science Center (PacSci) is an independent, not-for-profit institution with the mission to "[fuel] passion for discovery, experimentation, and critical thinking" (PacSci, n.d.b.). Their Science Communication Fellowship (SCF) Program is a tuition-driven program designed by and assessed with scientists and other STEMbased professionals to help create excellent communicators of cutting-edge work. Through interactive group workshops, SCF training familiarizes scientists with the learning sciences as well as with a variety of best practices in communicating their scientific expertise to the public. In consultation with mentors from PacSci's staff including author EAM, the scientists also develop hands-on activities that generate engaging conversations about the work they do. More details about the SCF Program are available elsewhere (Tisdal, 2011).

PacSci's philosophy is that visitors of all ages and abilities greatly benefit from interacting with and learning directly from scientists about the work they are performing. This learning most often takes place via Meet a Scientist, a recurring event at PacSci during which Science Communication Fellows engage the public through hands-on activities, speak with guests of all ages, and answer questions relating to their work. Meet a Scientist events occur on Saturday afternoons in a prominent location within the museum, when there are typically between 1,000 and 4,000 visitors present. In the decade since its inception, nearly 400 STEM-based professionals have participated in the SCF Program, and over 100 still actively volunteered with PacSci before its temporary closure due to COVID-19.

The Partnership: STEP Forward. STEP Forward was an official partnership between STEP-WISE and the SCF Program, with SCF tuition funded by a Career Guidance for Trainees grant from the Burroughs Wellcome Fund; the grant was co-written by representatives from both programs. Drawing from the pool of individuals who had already completed STEP-WISE, STEP Forward afforded these postdocs, who had previously developed expertise in classroom teaching, opportunities to expand their skill set to communicate well with the general public, as represented by guests at PacSci (Figure 1).

Participants in STEP Forward were solicited from the pool of 98 previous STEP-WISE graduates. Ultimately, 13 STEP-WISE graduates, one of whom was also a STEPWISE mentor (author EYM), participated in STEP Forward; of these 13 people, 12 completed the SCF trainings and volunteer commitments.

STEP Forward participants completed their STEP-WISE teaching apprenticeship between 5.5 years and four months prior to the start of their Science Communication Fellowship (SCF) experience. SCF training at PacSci consisted of two 


\section{STEP-WISE}

Science communication in the college classroom:

- Develop teaching skills that emphasize critical thinking and active learning.

- Build courses from the ground up.

- Gain teaching experience.

- Generate teaching portfolios and evidence of teaching.

\section{PacSci SCF}

Science communication with the museum-going public:

- Develop strategies to promote inquiry and engagement with diverse populations.

- Develop hands-on teaching tools.

- Participate in outreach and service to the public, disseminating scientific research and its relevance.

Figure 1. STEP Forward combined two existing programs: STEP-WISE focused on science communication within college classrooms, and PacSci's SCF Program focused on focused on science communication with the general public.

full-day Saturday workshops in autumn of 2017 that were separated by three weeks. This schedule is more condensed than the usual SCF training, which takes place over eight weeks, because much of the material overlapped with STEPWISE training. Facilitated by PacSci staff, these workshops were an opportunity for participants to broaden their expertise in teaching and facilitating discussions in classroom environments to include communicating in informal learning environments. Given the small group interactions typical at Meet a Scientist events, the training emphasized that learning is personal, teaching participants how to reach for connections with the people with whom they interact. As in STEP-WISE classrooms, PacSci staff emphasized the importance of conversation, questioning strategies, and making a scientific topic meaningful for each guest, thus avoiding one-way interactions.

In the three weeks between the two workshops, each STEP Forward participant developed a hands-on activity related to their work. PacSci staff members met with each participant during this time to discuss activity design and facilitation ideas, and provided subsequent support via email. The final hours of the second workshop were devoted to a group prototyping event, where STEP Forward participants showcased their hands-on activities for one another, previously-trained Science Communication Fellows, and PacSci staff. Each participant received verbal and written feedback from multiple testers to use in refining their activity before their first Meet a Scientist event.

Following the workshop series, STEP Forward participants were asked to present their activity in a minimum of three Meet a Scientist events within six months to practice the skills that they had learned. Having completed the full training series, they were considered Science Communi- cation Fellows at PacSci and were invited to participate in additional science education outreach events and training opportunities open to this volunteer group.

\section{DATA AND ANALYSIS}

Our data and analysis are qualitative and focused exclusively on the participants in STEP Forward. Qualitative analyses are appropriate when the populations studied are small and unique, as in this study (Patton, 2015). The population of STEP Forward participants differs from those who participated only in a single program - either STEP-WISE or SCF. STEP Forward participants were specifically interested in expanding their skill set to include communication with the general museum-going public and broadening their career aspirations to include opportunities outside of the academy. Conversely, most STEP-WISE fellows are interested in gaining teaching experience to ease their transition to becoming university faculty, whereas most SCF fellows are interested primarily in science outreach. The six fellows who had completed both programs prior to our formal collaboration represent a small sample of the total participants at the time (98 for STEP-WISE and 297 for SCF). Because the differences in populations among the three groups (STEP Forward, STEP-WISE, and SCF participants) make a statistical comparison inappropriate, we conducted a qualitative analysis of STEP Forward participants to understand their perceptions of what they gained from this experience.

Our evaluation data are from a series of four surveys that we administered at different times during participants' experience in the SCF Program (Table 1, Appendix): Pre-Training Survey, Training Feedback Survey, Program Review Survey, and Experience Survey. The Program Review Sur- 


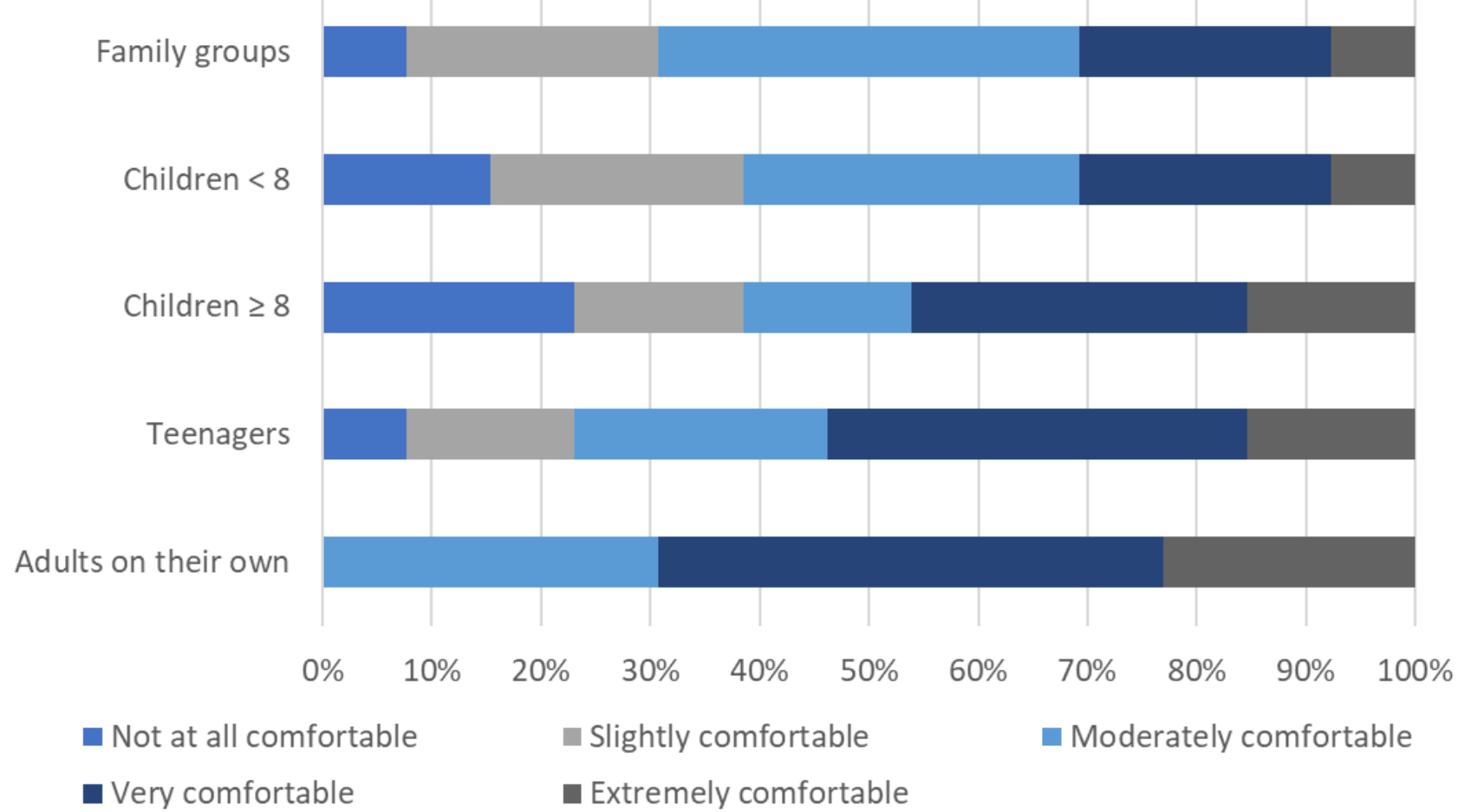

Figure 2. Comfort level that STEP Forward participants reported about talking to museum guests of different ages before their training began. $(\mathrm{N}=13$, including the one participant who completed training but did not attend any Meet a Scientist events.)

vey is administered to all SCF fellows at the same time each year, while the Experience Survey is administered to an individual cohort after fellows complete 2 or 3 Meet a Scientist events. Because these two survey periods overlapped for several STEP Forward participants, some participants completed the Experience Survey before completing the Program Review Survey. The Program Review Survey had a low response rate, but some of the open-ended responses were informative. Therefore, these data were considered alongside responses from the Experience Survey.

Two of us (EAM and RMP) applied content analysis to the survey data (Patton, 2015), reading through the responses and iteratively noting themes that emerged across all four surveys. The idea of emergent themes is critical in content analysis because it is an inductive approach that identifies themes within a data set, rather than a deductive approach that tests a hypothesis articulated before data collection, and thus particularly appropriate for program evaluation (Patton,

Table 1. Surveys used to assess STEP Forward participants' experience in the SCF Program.

\begin{tabular}{|c|c|c|c|}
\hline Survey & $\begin{array}{l}\text { N Completed } \\
\text { (out of 13) }\end{array}$ & Survey Launch & Description \\
\hline Pre-Training & 13 & Before beginning training & $\begin{array}{l}\text { Participants shared their motivations for becoming a Science } \\
\text { Communication Fellow, their comfort with communicating to } \\
\text { a general audience, and concerns they had before starting the } \\
\text { training. }\end{array}$ \\
\hline Training Feedback & 12 & Immediately after training & $\begin{array}{l}\text { Participants assessed training, commenting on aspects that were } \\
\text { particularly impactful and reflecting on how prepared they felt to } \\
\text { facilitate at Meet a Scientist events. }\end{array}$ \\
\hline Program Review & 5 & $\begin{array}{l}5 \text { months after training, as part of an } \\
\text { annual survey for all Science Com- } \\
\text { munication Fellows. Participants had } \\
\text { completed between } 0 \text { and } 3 \text { Meet a Sci- } \\
\text { entist events, with a mean and standard } \\
\text { deviation of } 1.9 \pm 0.9 \text {. }\end{array}$ & $\begin{array}{l}\text { Participants explained their interest in and motivations for con- } \\
\text { tinuing in the program. }\end{array}$ \\
\hline Experience & 9 & $\begin{array}{l}7 \text { months after training. Participants had } \\
\text { completed either } 2 \text { or } 3 \text { Meet a Scientist } \\
\text { events, with } 75 \% \text { having completed } 3 \text {. }\end{array}$ & $\begin{array}{l}\text { Participants shared ideas for improving the SCF Program, reflect- } \\
\text { ed on their interest in continuing to facilitate at PacSci events, } \\
\text { commented on their comfort with public-facing events, shared } \\
\text { how they felt about their SCF accomplishments, and indicated } \\
\text { how their experiences affected other aspects of their lives. }\end{array}$ \\
\hline
\end{tabular}


2015: 64). While this approach is useful for surfacing different themes, it is not appropriate for counting the number of times we encountered different ideas. This is because the absence of an idea in a response to an open-ended question does not indicate the respondent's attitudes towards or thoughts about that idea; instead, it indicates only that they were not thinking about the idea at the moment of the survey.

We also recorded the number of events at which participants facilitated their activities between December 2017 and December 2019.

The University of Washington found this research exempt from regulation by the Human Subjects Division of the Institutional Review Board (STUDY00006790).

\section{RESULTS}

Emergent Themes in Motivation and Confidence. Overall, participants indicated that STEP Forward was a beneficial and formative experience. We identified five primary themes about their experiences that emerged in our analysis of the qualitative feedback the participants provided (Table 2 - Table 6).

Theme 1: Society and the Value of Science Funding. A major goal of STEP Forward, and the primary goal of the SCF Program, was to increase scientists' ability to communicate with the general public. Two sub-themes on this topic emerged from our analysis (Table 2). First, some participants indicated that they wanted to communicate with the general public for the good of society. They indicated this as a goal in the Pre-Training Survey, and by the end of the training, recognized a number of elements in the SCF Program that would help them communicate science in a variety of contexts in the future. In general, they reported feeling more skilled at communicating science by the end of the experience. Second, they indicated that successful scientific communication is essential to securing federal funding for research. Some participants indicated this as an initial goal for participating in the program, and they returned to this idea again when reflecting about the entire experience.

Theme 2: Developing Activities for Delivery at Pacific Science Center. A major goal of the SCF Program is for each scientist to develop and facilitate a hands-on activity relating to their scientific expertise. This task was initially intimidating for some participants in the STEP Forward cohort, although support structure built into the program was reported to help ease that feeling (Table 3). Such structure included one-on-one activity development support from PacSci staff and getting feedback from staff and volunteers about the prototyped activities before using them with guests. As these activities began to take shape, some participants expressed excitement about using them. Prior to training, par-
Table 2. Society and the value of science.

The value of communicating about science

Pre-Training Survey

"feel strongly that improving communication between scientists and the community will benefit both parties"

"it is critical for scientists to communicate their science to the public in a way that the public can appreciate and understand. This is both important for the future of science (funding and recruiting new scientists) and for public good (getting the public to take advantage of scientific advances)."

"It is not enough to find something, you have to be able to tell other people about what you found and why you and they might find it interesting or important."

Training Feedback Survey

"I think this course helped me a lot in communicating my work better to people outside my field, and my family. It also helped me get a better perspective of an engaging two-way communication."

"I think that nearly every aspect of the course is applicable, helpful, and relevant to other areas of my life. As a scientist, member of the public, student, and teacher, communication skills and awareness are essential to my role."

"all communication skills are useful! building narrative, language choice etc are helpful every day as a scientist"

Program Review Survey and Experience Survey

"I feel valuable that I'm helping promote science literacy to a wide[r] audience than traditional classroom teaching experience."

"I like being able to contribute to scientif[i]c literacy, especially answering questions from people who may not know where to go for answers."

"I appreciate feeling like a community resource and I think I help make the world of DNA more accessible and less intimidating."

"I think a lot more about how I talk about my science both to scientists and non-scientists."

\section{Communicating about funding}

Pre-Training Survey

"it is critical for scientists to communicate their science to the public in a way that the public can appreciate and understand. This is both important for the future of science (funding and recruiting new scientists) and for public good (getting the public to take advantage of scientific advances)"

Program Review Survey and Experience Survey

"Public outreach is critical for engaging the public. Which is critical for continued public support of science research, encouraging the next generation of scientists, and helping the public use the scientific knowledge available."

ticipants self-reported how comfortable they felt discussing their work with guests of different ages (Figure 2). Later, as participants gained actual experience facilitating their activities at PacSci events, some reflected again on their comfort levels with different audiences; by then, many felt prepared to engage with children, a successful outcome given their earlier concerns about how to frame their research appropriately (Table 3 ).

Theme 3: Confidence. Although our surveys do not allow us to quantify the change in confidence about speaking with the public, the open-ended responses of some participants showed a general trend. The participants came equipped by 
Table 3. Developing activities for delivery at Pacific Science Center.

\section{Designing the activity}

Pre-Training Survey

"I am concerned about developing an interesting, simple, hands-on activity related to my research."

"I'm not sure what aspect of my research interests can be easily and accurately translated to engagement."

Training Feedback Survey

"It was challenging for me to generate a simple, yet clear activity with enough to do. My activity seemed to fall short on having too little information"

"The one on one support was by far the most useful. Being able to talk about ideas and get ideas on implementation took me from I think I might have an idea to this is going to be an awesome activity."

"The prototyping was very helpful to really think about my planned activity."

Program Review Survey and Experience Survey

"I was really impressed with how I came into the program with no idea of what I wanted to do or how I wanted to do it, and by the end of the day I had some great ideas to build on based on the advice and ideas in the workshop."

"I'm really proud of my demo."

\section{Delivering activity to different ages}

\section{Pre-Training Survey}

See Figure 2

Training Feedback Survey

"I'm most excited about interacting with families over the next year in the 'Meet a Scientist' program at the Pacific Science Center. I can't wait to witness and facilitate 'exploration' in such a beautifully diverse array of people!

Program Review Survey and Experience Survey

"I found myself knowing how to pitch my activity for little kids, but when it came to adults, I had some difficulty in switching 'talking Modes"”

"Being able to engage with children and their parents simultaneously." "This fellowship provided the guidance, support, feedback, and practice for me to eventually feel at ease discussing my project with audiences ranging from toddlers to politicians!"

"my favorite moment was when an $\sim 3$ yo boy remembered me from last time"

"I LOVE the $21+$ events."

STEP-WISE with the ability to communicate interactively, but some indicated that they felt nervous about speaking with visitors at PacSci. However, their confidence in that ability seemed to grow through the training they received (Table 4).

Theme 4: Participants Tie Experience to Classroom Teaching. Consistent with their previous experience in teaching through STEP-WISE, some participants indicated in the Pre-Training Survey that they were looking forward to the SCF Program because they wanted to improve their classroom teaching skills (Table 5). The SCF Program helped them meet that goal, with participants in general reporting that they would use the activities they developed in their classroom teaching and that they felt more qualified to help undergraduate students appreciate the nuances of the science
Table 4. Confidence.

\section{Pre-Training Survey}

"Nervous about generating a novel activity for use with the guests. I'm not sure about what idea I should generate."

Training Feedback Survey

"I feel surprisingly confid[e]nt."

"I'm sure I will get nervous, but I don't think any amount of prep will prevent that ;)"

Program Review Survey and Experience Survey

"I've also had enough practice now interacting and communicating with the public that also feel more comfortable talking science to non-science audiences."

"I am much better equipped to interact with non-scientists about science in any setting."

being taught. After completing Meet a Scientist events, some participants became much more aware of the jargon they used while communicating science and reported being much more able to communicate clearly to a general audience.

Theme 5: Scientific Careers and Identities. Some participants chose to surface ideas about career trajectory in their responses to open-ended questions. These participants indicated that, in general, the program supported their career goals and even reinvigorated their identities as scientists. Engaging with public audiences allowed them to develop and practice strategies that benefit them in a variety of professional environments, and to be reminded that despite the challenges encountered by those embroiled in it daily, science can be exciting and valuable (Table 6).

Table 5. Participants tie experience to classroom teaching.

\section{Pre-Training Survey}

"[I] am always trying to find different ways of explaining difficult scientific concepts to students, including pre-major and nonmajor students"

"This program would contribute greatly to my teaching of undergraduates"

"I think this training could also be useful to me for teaching."

\section{Training Feedback Survey}

"The course is very applicable to my work as an undergraduate teacher and also at home. I feel more equipped to talk about science to my family and also to students who may not have a very extensive scientific background."

"making science more approachable for undergraduates"

"I will likely use modified versions of this in my classroom teaching and laboratory mentoring."

Program Review and Experience Survey

"Now that I am aware of how much jargon I use, I am constantly catching myself in my use of jargon and trying to avoid it when I'm talking to others and when I'm teaching in the classroom."

"has definitely helped me in my own classroom teaching!"

"I am quite proud of the activity that I've developed on CRISPR. I've gotten lots of good feedback on this activity and I'd like to use it as part of my undergraduate teaching."

"I also modified my activity to use in a classroom demo (which was well received)." 
Table 6. Scientific careers and identities.

Pre-Training Survey
"Science communication is a vital part of my career development and
future goal to obtain a faculty position"
Program Review Survey and Experience Survey
"I have used this in everything from classroom visits to job talks."
"Volunteering at PacSci lets me add some teaching to my research
life."
"Daily scientist life can sometimes make me doubt my self-worth,
especially on days when experiments fail or I've just proven my
hypothesis incorrect. I think talking to people who [are] curious about
what I do or what I'm showing them helps me remember that I do love
doing science and what I do is important."
"reminding me of why I got started in science has helped improve my
daily attitude towards research"

Participant Involvement. All 13 STEP Forward participants completed their training and developed innovative activities that made their cutting-edge research relatable. Furthermore, 12 of them presented these activities at PacSci. One participant moved out of the area and was unable to facilitate any Meet a Scientist events. Of the projected 36 Meet a Scientist commitments from these 12 participants, 34 of these were completed between December 2017, when the training ended, and July 2018. The SCF Program typically sees this number of completed events within 12 months of training, so the STEP Forward cohort exhibited a particularly high level of commitment.

As of December 2019, these 12 participants have volunteered roughly 194 hours in public programming at PacSci. Five of these participants have gone well beyond the minimum commitment, participating in additional programming such as large research weekends and evening events focused on adult audiences. Five participants have also participated in additional training opportunities through the SCF Program, such as addressing controversial topics and/or storytelling. While some STEP Forward participants have now moved out of the area, six were actively volunteering at PacSci up until the temporary closure due to COVID-19.

\section{DISCUSSION}

STEP Forward supports the broader impact of preparing postdocs to communicate and disseminate science inclusively and effectively through intensive and directed training. As we anticipated, and as reported by the participants, this experience improved the skills and confidence for postdocs pursuing careers that require teaching and science communication. Here, we discuss the impact of the program on the participants and reflect on how others could build programs that are similar.

Impact of STEP Forward on Participants. Communicating science to the general public has a wide range of benefits for scientists. There is a direct, pragmatic gain that improved communication in multiple contexts can improve communication within one's particular field (Jensen et al., 2008). In addition, STEP Forward participants report feeling more confident in their abilities to communicate with a variety of audiences (Table 3, Table 4). Some participants also explicitly connected the training to improved skills in classroom teaching (Table 5).

The skills developed move beyond the classroom to contribute to a larger vision of science and society (Kuehne et al., 2014). Participants in STEP Forward had an opportunity to directly expose the public to science that is cutting-edge, local, and relevant to their lives. This opportunity was an effort about which many participants were eager (Pre-Training Survey responses and Training Feedback Survey responses in Table 2 - Table 6). This eagerness may be due to a sense of obligation to share their research (Table 2) and to speak with the general public about why conducting and funding scientific research are so critical (Table 2). In the survey responses reported here, many STEP Forward participants mentioned not only the benefits to themselves and their careers, but how they felt that their efforts in this program contributed to society more broadly.

Conversations with the general public reinvigorated how some of the participants felt about being scientists (Table 6) at a particularly precarious point in their careers (National Academy of Sciences, 2014). Postdocs typically have not had the time or opportunity to engage in science outreach earlier in their careers (Kuehne et al., 2014). During their postdoctoral fellowships, they are deciding what careers to pursue and aim to diversify their skills (National Academy of Sciences, 2014). Thus, the opportunity to participate in STEP Forward in a community to build skills with others who are also at an uncertain stage in their careers was particularly valuable (Table 6).

As the leadership team for this program, we have reflected on our own observations of how the partnership between STEP-WISE and the SCF Program benefited the participants. Framing STEP Forward as a dedicated cohort of the SCF Program facilitated many logistical details: for instance, organizers were able to seek funding to cover the tuition cost on behalf of the group rather than requiring each participant to separately find resources, and workshops were scheduled around participants' specific needs. Additionally, the official partnership encouraged the participants to consider the value of this training and to make time for it. While improving these skills does require time and effort, this partnership ensured that for postdocs willing to make such investments, the experience went as smoothly as possible. The postdocs in this cohort clearly built a community. Some knew each other ahead of time, and all shared the experience of STEP-WISE, in addition to all participants having common desires and goals around education and outreach that typical academic 
biomedical training experiences do not generally prioritize. Further, the cohort was welcomed into a larger established community of Science Communication Fellows with similar desires and goals.

Replicability. We anticipate that other institutions will want to replicate the impact of STEP Forward on the professional development of the participants. Consistent with previous studies, we have shown that linking together established training programs in formal and informal education can lead to strong partnerships (Chowning, 2020; Ito et al., 2013; Stocklmayer et al., 2010). While the exact nature of our collaboration may be hard to replicate, we have identified three aspects of our partnership that can help support early career scientists who seek to develop a breadth of science communication skills.

Identify Synergistic Programs. To build a program similar to STEP Forward, it can be helpful to find already-existing training programs that share a similar vision, but focus on developing complementary skills. Our impression is that in cities with science centers, there tend to be many opportunities that focus on supporting either formal or informal teaching, but few instances that combine the two. Here, the shared vision between STEP-WISE and SCF is to employ learner-centered instruction (Freeman et al., 2014; Stains et al., 2018) to communicate science, whether that is to museum guests or to undergraduate students in a classroom.

Because of their common focus on learner-centered instruction and dedication to scientific literacy, STEP-WISE and SCF share a number of programmatic elements. Training in the two programs is complementary, focused on active and project-based instruction. In fact, the activities prepared in the SCF Program can and have been used in classroom instruction as well (see Kao [2014], for example, as well as Table 5, Table 6). The participants who completed both programs are dedicated to sharing cutting-edge science, such as the CRISPR-Cas9 method for genetic engineering, in both formal and informal environments. Collaboration between two established programs can also be mutually beneficial by opening up new funding opportunities: the Burroughs Wellcome Fund grant that paid for participants' SCF tuition specifically sought to forge such collaborations among pre-existing programs.

Target a Population Seeking New Opportunities. Postdoctoral fellows, graduate students, and individuals at other career stages that encourage introspection can be eager to seize opportunities to broaden their skills in ways that include strengthening their communication abilities (Gibbs and Griffin, 2013; Gibbs et al., 2015). STEP Forward provided a structured way for them to do so. In this instance, our program participants are postdocs or former postdocs (within 5 years) who are still at a transitional stage in their careers. More abstractly, recruiting participants who anticipated professional benefits from the skills developed in the program enhanced their commitment to the program, and thus also the program's success.

Use a Pre-Survey to Ensure that Training Develops the Desired Skills. We found it helpful to consider what skills participants had already obtained, as well as the skills and experiences they desired to gain as an outcome of their participation in the complementary training program. Thus, the pre-training survey was critical for assessing what the participants sought from SCF, rather than offering those experiences in an ad hoc way. As demonstrated in Table 2, our participants felt compelled to improve the scientific literacy of the museum-going public, and they expressed regret that they had not yet done so in their careers (as in Kuehne et al., 2014). They also felt some trepidation about moving between their jargon-heavy research communities and a general audience (Table 3, Table 4) at the outset, but they overcame this trepidation and felt successful and skilled at their ability to communicate. A pre-survey can also allow facilitators to adjust the content to avoid teaching what participants already know, thus decreasing the time spent in training as we did.

Of course, surveying how participants respond to the experience at its conclusion is also valuable feedback and part of the formative data that can improve collaborations such as ours over time. Our participants valued a number of experiences that they did not anticipate, for example finding that they could deliver their hands-on activity in a variety of unexpected formats (Table 6), or that the Meet a Scientist events were something to look forward to when the daily grind of lab research became dull (Table 6).

\section{CONCLUSION}

Our STEP Forward partnership succeeded at giving postdoctoral fellows training and support to develop their communication skills and hands-on activities that teach sophisticated scientific concepts. Our results indicate that participants eagerly took part in public events at Pacific Science Center, gained confidence in speaking with the general public, and valued the opportunity to bring their scientific research to a broader audience. Collaborations such as this between universities and informal education institutions can energize researchers and the public alike in their scientific curiosity.

\section{ASSOCIATED CONTENT}

Supplemental material mentioned in this manuscript can be found uploaded to the same webpage as this the manscript. 


\section{AUTHOR INFORMATION \\ Corresponding Author}

Rebecca M. Price, University of Washington, Bothell, Box 35853018115 Campus Way NE, Bothell, WA 980118246. beccap@uw.edu

\section{Author Contributions}

The manuscript was written through contributions of all authors. All authors have given approval to the final version of the manuscript.

\section{ACKNOWLEDGMENTS}

We thank the postdoctoral fellows who participated in these programs, Pacific Science Center staff who run the SCF Program, and PacSci guests who visited participants' hands-on activities at Meet a Scientist events. We also thank Eve Klein, Victoria McGovern, and Ann McMahon.

\section{FUNDING SOURCE}

STEP Forward was funded by a Career Guidance for Trainees grant from the Burroughs Wellcome Fund from 2017-2018.

\section{ABBREVIATIONS}

EAM: Elizabeth A. McCullough; EYM: Eva Y. Ma; PacSci: Pacific Science Center; RMP: Rebecca M. Price; SAN: Salwa Al-Noori; SCF: Science Communication Fellowship; STEP: Science Teaching Experience Program; STEP-WISE: Science Teaching Experience Program Working in Science Education; UW: University of Washington

\section{REFERENCES}

Alberts, B., Kirschner, M.W., Tilghman, S., and Varmus, H. (2014). Aronson, E., and Bridgeman, D. (1979). Jigsaw groups and the desegregated classroom: In pursuit of common goals. Personality and Social Psychology Bulletin, 5.

Cameron, C., Lee, H. Y., Anderson, C., Byars-Winston, A., Baldwin, C. D., and Chang, S. (2015). The role of scientific communication skills in trainees' intention to pursue biomedical research careers: A social cognitive analysis. CBE Life Sciences Education, 14, ar46. doi: 10.1187/cbe.1409-0152

Chowning, J. T. (2020). The student biotechnology expo: A new model for a science fair. American Biology Teacher, 64, 331-339.

Clarke, J. (1994). Pieces of the puzzle: The jigsaw method. In S. Sharan (Ed.), Handbook of Cooperative Learning Methods (pp. 34-50). Westport, CT: Greenwood Press.
Crowe, A., Dirks, C., and Wenderoth, M. P. (2008). Biology in Bloom: Implementing Bloom's Taxonomy to enhance student learning in biology. CBE Life Sciences Education, 7, 347-430. doi: 10.1187/cbe.08-05-0024

Francek, M. (2006). Promoting discussion in the science classroom using gallery walks. Journal of College Science Teaching, 36, 27-31.

Fuhrmann, C. N., Halme, D. G., O'Sullivan, P. S., and Lindstaedt, B. (2011). Improving graduate education to support a branching career pipeline: Recommendations based on a survey of doctoral students in the basic biomedical sciences. CBE-Life Sciences Education, 10, 239-249. doi: 10.1187/cbe.11-02-0013

Gibbs, K. D., Jr., and Griffin, K. A. (2013). What do I want to be with my $\mathrm{PhD}$ ? The roles of personal values and structural dynamics in shaping the career iInterests of recent biomedical science PhD graduates. CBE-Life Sciences Education, 12, 711-723. doi: 10.1187/cbe.13-02-0021

Gibbs, K. D., Jr., McGready, J., and Griffin, K. A. (2015). Career development among American biomedical postdocs. CBE-Life Sciences Education, 14, 1-12. doi: 10.1187/ cbe.15-03-0075

Handelsman, J., Miller, S., and Pfund, C. (2006). Scientific Teaching: W. H. Freeman.

Ito, M., Gutiérrez, K., Livingstone, S., Penuel, B., Rhodes, J., Salen, K., Shor, J., Sefton-Green, J., and Watkins, S. C. (2013). Connected Learning: An Agenda for Research and Design (pp. 99). Irvine, CA: Digital Media and Learning Research Hub.

Jensen, P., Rouquier, J.-B., Kreimer, P., and Croissant, Y. (2008). Science and public policy.Science and public policy.: Scientists who engage with society perform better academically. Science and Public Policy, 35, 527-541. doi: I 0.3 I 52/030234208X329130

Kao, R. M. (2014). Of heart and kidneys: Hands-on activities for demonstrating organ function and repair. The American Biology Teacher, 76(8), 559-562. doi: 10.1525/ abt.2014.76.8.10

Kuehne, L. M., Twardochleb, L. A., Fritschie, K. J., Mims, M. C., Lawrence, D. J., Gibson, P. P., Stewart-Koster, B., and Olden, J. D. (2014). Practical science communication strategies for graduate students. Conservation Biology, 28, 1225-1235. doi: 10.1111/cobi.12305

Pacific Science Center. (n.d.a). Science Communication Fellowship. Retrieved January 15, 2020, from https:/www.pacificsciencecenter.org/fellowship/

Pacific Science Center. (n.d.b.). https://www.pacificsciencecenter. org/about/, retrieved October 6, 2020

Patton, M. Q. (2015). Qualitative Research and Evaluation Methods: Integrating Theory and Practice (4th ed.). Thousand Oaks, CA: SAGE Publications, Inc. 
Rybarczyk, B. J., Lerea, L., Lund, P. K., Whittington, D., and Dykstra, L. (2011). Postdoctoral training aligned with the academic professoriate. BioScience, 61, 699-705. doi: 10.1525/bio.2011.61.9.8

Sauermann, H., and Roach, M. (2012). Science PhD career preferences: Levels, changes, and advisor encouragement. PLOS ONE, 7, e36307. doi: 10.1371/journal.pone.0036307

STEP. (n.d.). Science Teaching Experience Program: Working in Science Education $\mid$ Science Teaching Experience Program.

Stocklmayer, S. M., Rennie, L. J., and Gilbert, J. K. (2010). The roles of the formal and informal sectors in the provision of effective science education. Studies in Science Education, 46(1), 1-44. doi: 10.1080/03057260903562284

Tisdal, C. (2011). Summative Evaluation: Comparative Case Studies of Implementation at Fives Sites (pp. 14). Seattle, WA: Pacific Science Center.

Wiggins, G., and McTighe, J. (2005). Understanding by Design (2nd ed.). Alexandria, Virginia: Association for Supervision and Curriculum Development. 